\title{
MODIFICATION OF THE OESTROUS CYCLE OF THE UNDER-FED RAT ASSOCIATED WITH THE PRESENCE OF THE MALE
}

\author{
K. J. COOPER AND N. B. HAYNES \\ University of Nottingham, School of Agriculture, \\ Sutton Bonington, Loughborough, Leicestershire
}

(Received 13th March 1967)

\begin{abstract}
Summary. The effect of dietary restriction on the oestrous cycle of Wistar strain rats was modified by the presence of the male. In the absence of the male, increasing irregularity of oestrous cycle with a significant lengthening of the cycle $(P<0.01)$ was observed with increase in the degree of inanition. The presence of the male had a significant effect $(P<0.01)$ on the cyclic behaviour of rats on the lowest planes of feeding, bringing these animals into oestrus earlier than expected.
\end{abstract}

It has been shown that stimuli associated with the male can have a marked influence on the reproductive behaviour of the female in a number of species. Whitten $(1956,1958)$ observed that both a shortening of oestrous cycles and a synchronization of oestrus in mice could be brought about by the presence of a male. Similar phenomena have been reported for the sheep (Schinkel, 1954), goat (Shelton, 1960) and rat (Hughes, 1964). Bruce (1959, 1960) has reported an allied effect in which recently mated female mice return to oestrus prematurely when exposed to strange males.

The establishment of an anoestrous condition in rats by dietary restriction has been demonstrated on many occasions (Carr, King \& Visscher, 1949) and it has recently been established that oestrous activity may be resumed in a group of such anoestrous rats subjected to the external stimulus of constant illumination (Piacsek \& Meites, 1965).

The effect of different levels of inanition on the reproductive behaviour of the rat is at present being investigated in this laboratory. In the course of the study it was observed that the tendency of rats to have an extended di-oestrous period or to become anoestrous under dietary restriction could be modified by stimuli associated with the presence of the male.

Eighty female rats of the Wistar strain, 12 to 14 weeks old (120 to $150 \mathrm{~g}$ ) and showing normal reproductive cycles of 4 to 5 days as determined by vaginal smears, were individually caged under a lighting regime of $12 \mathrm{hr}$ light/12 hr dark and allocated randomly to four equal groups. One group was fed without restriction and the remaining groups were given restricted 
diets of $75,62.5$ and $50 \%$ respectively of the unrestricted intake. The mineral and vitamin content of the proprietary ration used was adjusted so that all animals received the same daily levels. The rats were weighed and vaginal smears examined daily, from which the stage of the cycle was classified as pro-oestrus, oestrus, metoestrus or di-oestrus.

After 28 days, unrestricted mature males of the same strain were selected at random and placed with the females of the $50 \%$ and $62.5 \%$ groups each night for a period of 12 to $15 \mathrm{hr}$ until mating occurred. Vaginal smears were taken continuously and the day of mating determined by the presence of spermatozoa in the smear. The same procedure was adopted with the unrestricted and $75 \%$-fed groups except that, since the oestrous cycles were of the expected duration, males were introduced on the night of the first anticipated oestrus after 28 days.

The changes in the mean weight and average cycle length of the groups is shown in Table 1. The average values for all completed cycles in each group

TABLE 1

EFFECT OF RESTRICTIVE FEEDING ON THE MEAN OESTROUS CYGLE LENGTH OF RATS

\begin{tabular}{l|c|c}
\hline \multicolumn{1}{c|}{ Group } & Weight loss or gain (\%) & $\begin{array}{c}\text { Cycle length before } \\
\text { introducing male } \\
(\text { mean } \pm \text { S.E. })\end{array}$ \\
\hline Unrestricted intake & +20 to +30 & $4 \cdot 3 \pm 0 \cdot 01(120)$ \\
$75 \% \%$ & 0 to +10 & $6 \cdot 1 \pm 0.30(80)$ \\
$62.5 \%$ & -6 to -10 & $6 \cdot 2 \pm 0 \cdot 35(76)$ \\
$50 \%$ & -12 to -20 & $7 \cdot 6 \pm 0.52(45)$ \\
\hline
\end{tabular}

Twenty rats per group, number of cycles examined in parentheses.

before contact with the male show that the cycle length increased with increasing levels of inanition. The overall increase from the unrestricted to the $50 \%$-fed group is significant $(P<0 \cdot 01)$.

The inanition-induced increase in cycle length was due in the majority of animals to longer periods of di-oestrus with slight increases in the length of pro-oestrus and oestrus. In some animals showing more extreme effects of inanition, the situation differed in that vaginal smear examination showed periods of di-oestrus of 9 to 12 days and only a short period of oestrogen activity. Cyclic activity was in fact only detected by the presence of cornified epithelial cells for a period of about $12 \mathrm{hr}$.

Five animals in the $50 \%$ and one animal in the $62.5 \%$-fed group became anoestrous early in the experiment and failed to show any cyclic activity thereafter.

The initial presence of the male caused much more pronounced cyclic changes as indicated by the vaginal smear in the $62.5 \%$ and $50 \%$-fed groups. This effect decreased with time in females which did not mate at the first oestrus. The vaginal smears of the unrestricted and $75 \%$-fed groups were essentially normal throughout and were not visibly aitered by the presence of the 
male, although any effect of the male on the length of the cycle could not be investigated in these groups since the male was placed with the female at a predetermined time.

The random introduction of the male had two obvious effects on the cyclic behaviour of rats at the lower levels of feeding. Firstly, an oestrous period always occurred shortly after the introduction of the male (Text-fig. 1:a and c)
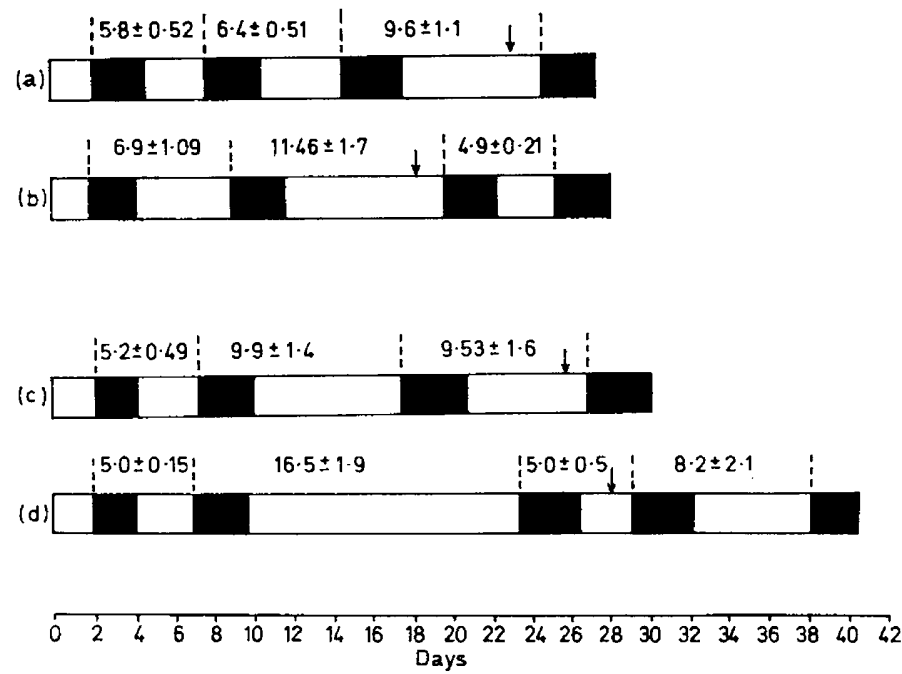

\begin{abstract}
TEXT-FIG. 1. Average cycle lengths of rats fed $62.5 \%$ and $50 \%$ unrestricted intake: (b) and (d) are subgroups from (a) and (c), respectively, and contain the rats which continued to cycle after introduction of the male. (a) $62.5 \%$, nineteen rats; (b) $62.5 \%$, seven rats; (c) $50 \%$, fifteen rats; (d) $50 \%$, four rats. Arrow indicates when the male was introduced. Solid bars, pro-oestrus, oestrus and metoestrus; unshaded bars, di-oestrus. Values between vertical broken lines, mean cycle length \pm S.E.
\end{abstract}

regardless of the previous stage of the cycle. The difference between the proportion of females showing induced oestrus and the proportion calculated to be in mid-cycle when the male was introduced is significant $(P<0.01)$. Secondly, the subsequent cycle length in animals which failed to mate at the first oestrus after introduction of the male was shorter than it had been before the male was introduced (Text-fig. 1: b and d) despite a continued loss in body weight. The extent to which dietary restriction prevented normal cyclic behaviour and the response made to stimuli associated with introducing the male varied between rats. A body weight loss of 10 to $15 \%$ appeared to be necessary to cause irregular cyclic behaviour and it was at this degree of restriction that the effect of the male was most obvious.

The endocrine changes responsible have not been investigated but it seems likely that a nutrition-induced pituitary block in terms of FSH and LH secretion is being removed by the presence of the male. It has been suggested that odours from the male initiate FSH and LH secretion by hypothalamic stimulation and give rise to the Bruce effect (Bruce, 1963; Dominic, 1966a, b). A similar explanation could account equally well for the phenomenon described in this communication. 


\section{REFERENCES}

BRUGe, H. M. (1959) An exteroceptive block to pregnancy in the mouse. Nature, Lond. 184, 105.

BRUCE, H. M. (1960) A block to pregnancy in mice caused by the proximity of strange males. F. Reprod. Fert. 1, 96.

BrucE, H. M. (1963) Olfactory block to pregnancy among grouped mice. F. Reprod. Fert. 6, 451.

CARR, C. J., KING, J. T. \& Visscher, M. B. (1949) Delay of senescence infertility by dietary restriction. Fedn Proc. Fedn Am. Socs exp. Biol. 8, 22.

Dominic, C. J. (1966a) Observations on the reproductive pheromones of mice. I. Source. F. Reprod. Fert. $11,407$.

Dominic, C. J. (1966b) Observations on the reproductive pheromones of mice. II. Neuro-endocrine mechanisms involved in the olfactory block to pregnancy. 7. Reprod. Fert. 11, 415.

Hugues, R. L. (1964) Effect of changing cages, introduction of the male, and other procedures on the oestrous cycle of the rat. C.S.I.R.O. Wildl. Res. 9, 115.

Piacsek, B. E. \& Mertes, J. (1965) Reinitiation of gonadotrophin release in starved rats by constant light or adrenalin. Program of 47th Meeting of the Endocrine Society, p. 117 (Abstract).

Schinkel, P. G. (1954) The effect of the ram on the incidence and occurrence of oestrus in ewes. Aust. vet. F. 30, 189.

Shelton, M. (1960) Influence of the presence of a male goat on the initiation of oestrus, cycling and ovulation of the angora doe. F. Anim. Sci. 19, 368.

Whrrten, W. K. (1956) Modification of the oestrous cycle of the mouse by external stimuli associated with the male. F. Endocr. 13, 399.

Whrrten, W. K. (1958) Modification of the oestrous cycle of the mouse by external stimuli associated with the male. Changes in the oestrous cycle as determined by vaginal smears. F. Endocr. 17, 307. 